\title{
TRABALHO DE CAMPO NA (RE) CONSTRUÇÃO DA PESQUISA GEOGRÁFICA: REFLEXÕES SOBRE UM TRADICIONAL INSTRUMENTO DE INVESTIGAÇÃO
}

\author{
GISELA AQUINO PIRES DO RIO
}

Universidade Federal do Rio de Janeiro

\section{Introdução}

Que lugar ocupa o trabalho de campo nas pesquisas em Geografia? $\mathrm{Ou}$, mais especificamente, que espaço tem sido (ou não) reservado ao levantamento de dados primários nos projetos de pesquisa? Essas talvez não sejam questões espaciais originais e fundamentais para outras ciências sociais, mas, como veremos mais adiante, causam revelações surpreendentes na análise geográfica. Seguindo as várias referências sobre a construção intelectual e representação do objeto de pesquisa, e da própria pesquisa, podemos nos indagar sobre a atualidade dessa prática tão antiga no corpo da disciplina.

É sempre possível lembrar Walter Benjamin e seu questionamento a respeito da influência da fotografia em concepções consolidadas sobre a arte. Menos interessado no debate sobre a essência [da arte] da fotografia e mais inquisidor sobre a extensão das mudanças na concepção de arte provocadas pela fotografia e pelo fotografar, Walter Benjaim (1892-1940) oferece-nos matéria instigante para confrontar sua análise com as tendências atuais de produção de teses e dissertações. Considerar o trabalho de campo como procedimento que fornece uma imagem da área de estudo, ou ainda como a ferramenta que permite superar "a dicotomia sociedade- natureza" (ALENTEJANO e ROCHA LEÃO, 2006), "as dicotomias e ambiguidades características da geografia" (SERPA, 2006), remete, no meu entender, às consequências de padronização de imagens que, cada vez mais acessíveis, tornam-se banais. Interessa-nos, portanto, investigar em que medida o trabalho de campo altera nossa relação com o objeto de pesquisa. Por que nunca nos indagamos sobre isso ?

A motivação para este trabalho vem de duas experiências recentes. A primeira, está associada às atividades de docência em nível de pós- 
graduação. Em recente seminário de doutorado ${ }^{1}$, por mim coordenado junto ao Programa de Pós-Graduação em Geografia - PPGG/UFRJ, propus como problemática geográfica e transversal à Geografia humana e física, o estudo das relações sociedade-natureza. Em torno dessa problemática epistemológica, sete questões foram propostas para que os doutorandos refletissem, reelaborassem e desenvolvessem durante o período. Dentre as questões propostas, havia especificamente uma sobre o trabalho de campo ${ }^{2}$. Essa questão, aliás, como nenhuma outra, não foi elaborada de modo a superar qualquer dicotomia. Havia, contudo, a possibilidade de se discutir objetos híbridos (LATOUR [1991] 1994; ROBBINS, 2007).

A segunda motivação, que decorre da primeira, vem do levantamento bibliográfico para a preparação do seminário, delimitação e problematização dos temas que seriam objeto de apresentação e debate por parte dos alunos. O primeiro contato que tive com alguns dos artigos sobre trabalho de campo remetia a levantamento anterior quando ministrava, juntamente com diferentes professores ${ }^{3}$, a disciplina de graduação "Trabalho de Campo". Havia, portanto, uma base da qual partia a reflexão sobre o papel do campo na determinação do objeto e uma espécie de grade analítica para enfrentar o desafio dessas disciplinas que são chamadas a desenvolver efetiva transversalidade.

A terceira motivação decorre de minha experiência em pesquisa. Nesse sentido, essa motivação remete a minha própria formação e, mais recentemente, à experiência adquirida com projetos integrados de pesquisa, tanto aqueles sob minha coordenação, como naqueles dos quais participo na qualidade de colaboradora e membro efetivo da equipe. Nesse segundo caso, destaco os projetos Gouvernance des réseaux énergétiques et développement des territoires dans les pays émergents d'Amérique du Sud ${ }^{4}$ e "Novas Fronteiras do Biodiesel na Amazônia: limites e desafios da incorporação da pequena produção" ". Em todos os casos houve

${ }^{1}$ Disciplina obrigatória do curso de doutorado do Programa de Pós-Graduação em Geografia da UFRJ, que permite que se trabalhe questões associadas a determinada temática.

${ }^{2}$ Em 2002, Ana Maria Daou organizou o mesmo seminário-disciplina tendo como tema central o trabalho de campo.

${ }^{3}$ Disciplina com número elevado de créditos era, durante a vigência do currículo único (1990-2008) no Departamento de Geografia, ministrada por dois professores, em geral, um vinculado à Geografia física e outro à Geografia humana.

${ }^{4}$ Este projeto, sob a coordenação de Sébastien Velut conta com apoio do Institut de Recherche pour le Développement (IRD), França.

${ }^{5}$ Este projeto é coordenado por Julia Adão Bernardes e conta com apoio do CNPq. 
necessidade de construir caminho transversal na concepção e realização do trabalho de campo.

Trata-se, no âmbito mais geral, de reflexões a respeito da pesquisa em nível de pós-graduação e, em âmbito mais específico, do papel de disciplinas nas quais podemos congregar visões que convergem, divergem ou justapõem-se frente a determinado objeto ${ }^{6}$.

\section{.O seminário-disciplina: dois ou três esclarecimentos a respeito das opções efetuadas}

Disciplina obrigatória no curso de doutorado do Programa de PósGraduação em Geografia, o Seminário de Doutorado apresenta, desde o início da criação do curso, livre estrutura de organização. Como não há um único professor responsável pela disciplina, temas, princípios e metodologias são variáveis. Nessa característica reside o interesse da disciplina, pois evita a consolidação de posturas fundamentalistas no que diz respeito às bases conceituais e metodológicas da Geografia. Não sei se podemos considerar tal característica como tributária de incredulidade em relação às metanarrativas. Acredito, porém, que evita a cristalização e imposição de uma única visão, sejam aquelas que, em nome de cientificidade indefinida, tentam impor modelos naturalistas, sejam aquelas vinculadas a projetos individuais de pesquisa.

Em minha concepção, que não pode nem deve ser tomada como a melhor e, muito menos, a única possível, o seminário-disciplina pode desempenhar papel importante na revisão do projeto de pesquisa. Sua função é, antes de tudo, estimular e desafiar os doutorandos em suas trincheiras cavadas no esforço de mestrado acelerado e hiperespecializado ou, quando muito, continuação do trabalho de monografia. Defendo essa concepção na medida em que os doutorandos, cada vez mais jovens, iniciam o curso de doutorado recém-egressos do mestrado. Na maioria das vezes confunde-se a dissertação com o projeto de doutorado. Considero a provocação ainda mais importante diante de projetos cujo grau de verticalização chega a tal nível que é quase impossível encontrar sua geograficidade. E, por fim, defendo essa concepção por compreender que o doutorado constitui a grande oportunidade para treinamento no campo da pesquisa geográfica, bem como para ampliarmos nosso próprio conhecimento sobre o campo disciplinar.

\footnotetext{
${ }^{6}$ Não apresento notas de curso; tenho apenas a intenção de discutir posicionamentos que, a meu ver, estão arraigados na pouca reflexão sobre o próprio campo de conhecimento.
} 
Há continuidades e diferenças entre o primeiro seminário que organizei, em 1996, e o mais recente, em 2009. A continuidade reside na escolha de um único tema como fio condutor. O primeiro foi organizado em torno do tema Geografia do Brasil sob diferentes focos na virada do século. No seminário mais recente, adotou-se por fio condutor as relações sociedade-natureza discutidas a partir de questões-tema a elas vinculadas. As diferenças estão na forma de organização e na ênfase da reflexão sobre a produção de conhecimento, a relação empiria e teoria e na própria reflexão sobre a metodologia e a pesquisa de cada um. Os diferentes focos da geografia do Brasil foram trabalhados por professores-pesquisadores de vários programas de pós-graduação. Recentemente optamos por reduzir o número de convidados e ampliar a responsabilidade dos doutorandos como modo de alargar os respectivos horizontes conceituais. Outra diferença reside na orientação do seminário-disciplina: enquanto em 1996, a disciplina intitulava-se Seminário de Doutorado em Geografia Humana, em 2009, o curso intitulou-se Seminário de Doutorado, incluindo os alunos de todas as áreas de concentração do Programa. A opção por uma ou outra orientação, assim como a escolha da temática resultam da proposta de método e estratégia de discussão que o coordenador do semináriodisciplina se propõe a desenvolver. Enquanto no primeiro curso havia uma preocupação de discussão contextual, minha ambição foi, no mais recente, a de estimular a reflexão metodológica por parte dos doutorandos.

\section{.O trabalho de campo como elemento investigativo revelador de questões espaciais e de discussões surpreendentes}

$\mathrm{Na}$ apresentação dos temas, dois deles geraram certo espanto. $\mathrm{O}$ primeiro tema, por sua aparente obviedade: "o papel do trabalho de campo na pesquisa em Geografia". O outro, por ser, à primeira vista, inusitado: "as unidades de conservação como objeto híbrido de gestão".

O primeiro tema buscava traduzir a tensão na reciprocidade da questão sobre em que exatamente o trabalho de campo fundamenta a pesquisa e, de modo inverso, em que a pesquisa fundamenta o campo. A aparente obviedade da questão traduziu-se na reprodução de expressões como "imprescindível para a pesquisa", "rico em informações", "determinante para coleta de material", "o campo permite observar as relações entre teoria e prática" e tantos outros adjetivos e considerações, não raro, desacompanhados de reflexão rigorosa. Teses e dissertações são igualmente pouco reflexivas a esse respeito e raramente problematizam o papel do trabalho de campo quando este é realizado. Percebe-se, com 
grande frequência, a ausência do exame efetivo do campo em sua variedade $^{7} \mathrm{e}$, em alguns casos, das práticas adotadas (DeLYSER e STRARRS, 2001).

O segundo tema estava diretamente apoiado na concepção de Latour ([1991] 1994) sobre a ruptura fundamental da modernidade jamais vivenciada em sua plenitude e a invasão [bárbara] de híbridos em nosso cotidiano e, de outro, na tradução geográfica realizada por Santos (1996) que define o espaço geográfico como híbrido para suplantar o "equívoco epistemológico herdado da modernidade"... "já que a realização concreta da história não separa o natural e o artificial, o natural e o político" (SANTOS, 1996: 81). Não aprofundaremos esse tema no presente trabalho. Remetemos a alguns poucos exemplos que desenvolveram a ideia de objetos híbridos como aqueles que adquirem sentido no processo de gestão (SWYNGEDOUW, 2001; PIRES DO RIO, 2008) ou na análise de elementos não humanos na realidade geográfica (ROBBINS, 2007).

A opção pela discussão do trabalho de campo no presente artigo deve-se à ausência de candidatos ao tratamento do tema nos trabalhos finais. Enquanto todos os demais temas, inclusive as unidades de conservação como objetos híbridos, foram discutidos, ninguém se candidatou a enfrentar o desafio e problematizar o trabalho de campo na construção da pesquisa ou as implicações dessa tradição nos trabalhos atuais, de modo a dialogar com outro tema do curso. Ausência de referências bibliográficas sobre o tema não explica, pois é possível constatar número expressivo de títulos, ainda que apresentem densidade bastante variável.

Recuperar trabalhos como os de Ruellan (1944) ou Tricart ([1977] 2006) constitui, no nosso entender, uma das muitas possibilidades de recorte a ser adotado para um trabalho sobre o tema. A comparação entre os artigos daqueles que foram formadores de grande parte dos geógrafos no Brasil, em momento de consolidação da disciplina, reflete de modo bastante ilustrativo a maneira como digerimos, produzimos e reproduzimos nossas tradições.

\footnotetext{
${ }^{7}$ Sempre é bom lembrar que o tipo de trabalho de campo varia em função de seu objetivo: reconhecimento; levantamento de questões espaciais; coleta de dados; confirmação/refutação de hipóteses; questionamentos de posições consagradas etc.
} 


\section{A construção do tema como tradição da Geografia: uma possibilidade}

Quais seriam as razões para a carência de reflexão observada na formação recente dos geógrafos? Na preparação para o curso, a leitura do livro L'Enquête de terrain organizado por Daniel Céfaï, publicado em 2003, revelou a atualidade dos questionamentos e o amplo contexto da problemática e do campo como fonte de trabalho reflexivo e crítico. Ao recuperar textos clássicos, o autor apresenta as principais linhas dos debates, origem e modalidades do trabalho de campo em ciências sociais. Essa leitura condicionou a condução da discussão durante o seminário ${ }^{8}$ e revestiu-se de importância particular pelo exemplo de pesquisa em vários sentidos: da seleção e reunião de textos dispersos que foram traduzidos para o francês, da forma de apresentação e do aprofundamento da discussão de questões associadas ao trabalho de campo que não é muito familiar no momento atual da Geografia brasileira.

De modo semelhante, os editoriais escritos por DeLyser e Starrs (2001) e Driver (2000), assim como o capítulo escrito por Stoddart e Adams (2004), desempenharam importante papel na reflexão sobre as razões de certo abandono, não da prática em si, mas da análise do trabalho de campo como prática de pesquisa. $\mathrm{O}$ trabalho de campo tem longa história na Geografia e seu papel na pesquisa de curto e longo prazos varia espacial e temporalmente (GERBER e CHUAN, 2000). De modo geral, há certa convergência para considerar essa prática, que permite levantar informações através de entrevistas ou recuperar a história oral; não é nata, constitui aprendizado (DeLYSER e STARRS, 2001); ;desempenhou e desempenha papel central na construção da imaginação geográfica e mesmo na definição do objeto de investigação histórica (DRIVER, 2000). O trabalho de campo é igualmente prática social, que envolve distanciamento, e lugar de pesquisa, onde o conhecimento é gerado e registrado através de atividades específicas (STODDART e ADAMS, 2004).

8 Foi de fundamental importância, para o aprofundamento do tema, a participação dos professores Ana Maria Daou, Maria Célia Nunes Coelho e Roberto Lobato Corrêa no seminário. Ana Daou apresentou reflexão substantiva enriquecida por larga experiência de campo. Maria Célia Nunes Coelho, cujos trabalhos têm como característica rara combinação reflexiva entre empiria e teoria, apresentou poderosa argumentação crítica nas discussões. Roberto Lobato, igualmente com larga experiência, apontou a importância da Revista Brasileira de Geografia como veículo de difusão de um tipo de concepção de trabalho de campo. 
O levantamento de textos em português que tratassem especificamente sobre trabalho de campo em Geografia revelou pontos importantes, dentre os quais a existência de revista dedicada à publicação de artigos referentes às aulas de campo. Seu primeiro número data de 2006. Trata-se, portanto de publicação seriada anual recente. Com nome bastante sugestivo, a revista "Mirante", vinculada ao Núcleo Geográfico de Aulas de Campo da Universidade Estadual de Goiás, traduz, em grande medida, a delicadeza da questão metodológica e do status do trabalho de campo em Geografia nos textos que se dedicam ao tema. Até setembro de 2009, havia três números disponíveis em linha9. Nas duas primeiras edições, 2006 e 2007, detectamos quase o mesmo número de artigos sobre o tema, respectivamente, 4 e 3 . A edição de 2008 não apresentava nenhum artigo que indicasse, no título, uma análise sobre o trabalho de campo em qualquer acepção.

Em registro semelhante, trabalhos como o de Fonseca e Kuvasney (2002), publicado na revista Geousp e igualmente disponível em linha, limita-se a estabelecer um roteiro de observação sobre a estruturação da paisagem em determinada área de estudo. Transpõe a definiç̧ão de multidisciplinaridade como "justaposição de várias disciplinas" 10 para o trabalho de campo que congrega aspectos da geografia industrial, agrária e da fisiologia da paisagem. A revista Geousp dedica regularmente uma seção às experiências de campo, sob o título "Notas de Pesquisa de Campo". Assim como o trabalho de Fonseca e Kuvasney, que acabamos de mencionar, Huertas (2007), Silva (2004) e Azevedo et al (2003) pouco revelam das ideias que deram sentido aos respectivos trabalhos de campo.

A digitalização do Boletim Paulista de Geografia ${ }^{11}$ tornou acessível, no número 84, que trata sobre o tema trabalho de campo, textos importantes como A pesquisa e o trabalho de campo: um problema político para os pesquisadores, estudantes e cidadãos, de Yves Lacostem e O geógrafo e a pesquisa de campo, de Bernad Kayser- que já haviam sido traduzidos e publicados pela AGB, em 1985, na série "Seleção de Textos" número 11. Ao lado de contribuições mais recentes, aqueles permanecem como referências incontornáveis. Tanto quanto textos mais antigos, os artigos de Lacoste e Kayser mostram as preocupações com a função do

${ }^{9}$ Neste trabalho optou-se por utilizar a expressão disponível em linha no lugar do recorrente on line. Essa opção constitui esforço de ampliar as possibilidades de expressão em língua portuguesa.

${ }^{10}$ As autoras referem-se ao trabalho de Hilton Japiassu, "A interdisciplinaridade e a patologia do saber", publicado em 1976.

${ }^{11}$ http://www.agbsaopaulo.org.br/node/156 
campo no trabalho de pesquisa. Em ambos, encontramos a preocupação com o estatuto político da pesquisa e do pesquisador (KAYSER, [1977] 1985) ou, como nos lembra Céfaï (2003), as opções não são jamais exclusivamente metodológicas: elas se vinculam aos horizontes éticos e políticos do pesquisador.

Embora represente esforço considerável de didática e sistematização, não há, em nenhum desses trabalhos, enfrentamento do objeto de pesquisa. Ao contrário, o ponto de partida mobiliza um conjunto de conhecimentos, ferramentas e procedimentos que alimentam narrativas, descrições e roteiros, mas não evidencia que a realização do trabalho de campo comporta a construção do dado que se quer. Objetivos e justificativas para sua realização são claros, mas, ao contrário, o campo não é apresentado como parte do conhecimento para a compreensão ou experiência de algum modo desconcertante, envolvendo os imponderáveis da vida social que, na perspectiva antropológica, são sempre valorizados.

\section{Trabalho de campo: debate metodológico necessário?}

Ainda que seja pertinente a crítica, algo contundente, de Alentejano e Rocha-Leão (2006: 64) sobre os riscos de banalização de "uma tradicional ferramenta da Geografia" no mundo "onde imagem e paisagem são valorizadas em si mesmas", em um momento em que a "geografia do turismo se desenvolve no rastro da mercantilização crescente da vida e do mundo", o trabalho de campo permanece sendo visto como importante ferramenta da Geografia (GERBER e CHUAN, 2000; STODDART e ADAMS, 2004; DeLYSER e STARRS, 2001; SUERTEGARAY, 2002).

Do reconhecimento dessa importância não deriva, todavia, questionamento sobre a própria produção de dados, as contingências de observação ou as hipóteses levantadas. Nas defesas de teses e dissertações, em muitas das apresentações, o trabalho de campo é praticamente ignorado, quando muito mencionado de modo rápido ou, no máximo, como referência que localiza e situa a origem do material coletado, os procedimentos de laboratório ou o lugar da realização de entrevistas ou aplicação de questionários. Como, porquê e quando de sua realização não integram os elementos mobilizados para a construção do objeto, ou ainda, o campo em nada contribui para a objetividade da análise. Esta, por sua vez, será assegurada pelos procedimentos operacionais do laboratório. Em decorrência, o campo não se explica, nem se transmite, o campo se faz. "Hiper, super, megaimportante" para a Geografia (mas não só), o trabalho 
de campo, assim considerado, preexiste à construção do objeto ${ }^{12}$. Nessa perspectiva, toma-se o campo como realidade física e evidente que foge à elaboração intelectual.

No plano epistemológico, os textos publicados por aquelas revistas apontam, em linhas gerais, para o campo como evidência e procedimento operacional intrinsecamente associados a qualquer pesquisa. Constata-se postura diametralmente oposta àquela já assinalada por Kayser ([1977]1985:25): "Não se pode falar em pesquisa de campo em geral, nem mesmo em pesquisa de campo geográfica se não se define do que se trata". Chama atenção naqueles textos o fato do campo ser invariavelmente compreendido como estratégia para aprendizado e naturalizado como etapa quase obrigatória ao mesmo tempo em que esse último autor constitui referência amplamente utilizada.

Demangeon (1916-2007), em entrevista publicada recentemente (DAUDEL, 2008:69), considerou necessário esclarecer dois sentidos de campo que, na sua vida profissional, foram importantes: o campo como realidade da paisagem natural, mais adequado às estratégias de pesquisa em geomorfologia, em sua busca pela compreensão da realidade topográfica e estudo de configurações morfológicas em seu conjunto, e o campo como compreensão mais ampla, significando o lugar onde se deve ir para encontrar realidades geográficas a que nos propomos estudar. Não estaríamos aqui diante de autêntica questão metodológica?

$\mathrm{Na}$ tradição da concepção de campo como trabalho de geógrafo, Ruellan (1944) sintetizou de modo cabal a importância do campo para "chegar à descoberta de novas relações entre os fatos e as novas interpretações de geografia regional" (RUELLAN, 1944:35). Nesse artigo, destinado aos jovens pesquisadores, o autor considera que o trabalho de campo:

... não deve somente ajustar alguns complementos
interessantes ao conhecimento de um país, de uma região ou
de um fenômeno de geografia geral física, humana ou
econômica, mas também de controlar cuidadosamente as
observações e as interpretações dos predecessores, para
confirmá-las, completá-las, graduá-las ou mostrar o que têm
de inexato, a fim de chegar à realização de um trabalho de

${ }^{12}$ Poucos foram os artigos que trataram da relação sujeito-objeto. Exceção seria o artigo de Suertegaray (2002) que, resumidamente, exemplifica os diferentes métodos e a relação sujeito-objeto neles considerada. 
conjunto original por tudo que traz de novo sobre o assunto (RUELLAN, 1944:39).

Daí a ênfase no que fazer no campo: reconhecimento e análise das formas elementares do relevo, levantamentos topográficos expeditos, relações entre relevo e estrutura, estado atmosférico, regime dos rios, aspectos biogeográficos, formas, situações e distribuição do habitat rural. Para concluir que aí reside a verdadeira tarefa do geógrafo ${ }^{13}$.

Em registro distinto, o trabalho de Tricart (2006[1977]:104) estabelece sua opinião nos seguintes termos: "Não existem métodos próprios de Geografia, mas métodos de aplicação mais geral cujo uso pela Geografia é só um caso entre outros". É, portanto, a partir desse ponto de vista que Tricart defende, no plano metodológico, a necessidade da dialética campo-experimentação e campo-modelos físicos, considerando que "essa dialética assinala certos objetos ao conhecimento do campo" (TRICART, 2006:106). Em sua crítica, Tricart indica que, diante do aumento no uso de instrumentos que ampliam nossa capacidade de percepção e de dedução, "impõe-se uma estratégia de pesquisa: a superabundância de informação acessível e disponível (...registros de satélites, as coberturas de fotografias aéreas) obriga a fazer uma escolha, a selecionar certos tipos de informação que serão tratadas de acordo com as regras de arte" (TRICART, 2006:106). Neste artigo, surpreendentemente pouco comentado, encontramos substancial material para debate. Para Tricart, o trabalho dos geógrafos ligados à Geografia humana estaria aparentemente facilitado pela produção oficial de estatísticas, porém havia [e ainda há] a armadilha de tomar o sintoma pela doença. Em suas palavras "o trabalho de campo, isto é, inquéritos e observações pessoais" constituía em estratégia para escapar ao círculo vicioso da produção de estatísticas (TRICART, 2006[1977]:107).

No plano metodológico, na maioria dos textos que encontramos sobre o assunto, bem como nas teses e dissertações nas quais estivemos presentes em bancas, quer de qualificação, quer de defesa propriamente dita, o trabalho de campo, quando realizado, não distingue o modo de aproximação ao objeto de estudo. Poucas são as tentativas de discernir a utilização do campo como técnica de investigação empregada na construção do objeto e do conhecimento. Em ambos os casos, o trabalho de campo não é, em sua essência, problematizado. Mais do que um único

${ }^{13}$ Abreu (1994) ressaltou a importância do campo para os primeiros geógrafos, lembrando que Aroldo de Azevedo o considerava como $o$ trabalho do geógrafo. 
modelo de campo, a dialética proposta por Tricart questiona a relativa estabilidade no estudo das questões da natureza nos seguintes termos:

Com efeito, a opinião pública ressente-se cada vez mais profundamente da alteração de seu quadro existencial, o perigo biológico em que as poluições a colocam. O instinto de conservação entra em jogo: é mais forte que os xaropes políticos lenitivos. "Há coisas no ar" ainda nas regiões conformistas, como a Alsácia ou o país de Bade. Os tecnocratas se defrontam com um obstáculo que acreditaram ter neutralizado mediante o jogo combinado dos procedimentos administrativos e da informação truncada. Daqui a pouco, poder-se-á prever que a qualidade das águas e a poluição do ar, as doses da radiação e os dejetos térmicos serão objeto de medidas oficiais estabelecidas, como o PNB, e que haverá alguém que pretenderá dar explicações semelhantes àquelas de um engenheiro das minas oficiais de potassa da Alsácia. "Mas, afinal de contas, o cloreto de sódio não pode poluir, pois é solúvel". (TRICART, 2006[1977]:107)

Um dos argumentos de Stoddart e Adams (2004) diz respeito à grande capacidade da Geografia no diálogo e definição de política com outras áreas de conhecimento e a consequente necessidade, por parte dos geógrafos, em prestar mais atenção aos conceitos-chave e métodos que a distinguem de outras disciplinas, bem como àquilo que a aproxima dos demais campos das ciências sociais. Alguns pontos podem orientar a reflexão sobre esse último aspecto, principalmente em relação a esse tipo de pesquisa realizada em outras disciplinas.

O primeiro ponto a chamar a atenção é a perda de importância dos Guias de Excursão como fonte de informação e de esforço intelectual requerido na busca das marcas e processos que ali são identificados, observados e descritos. Há nesse tipo de material discussão de questões e metodologias inovadoras, que nos permitem mapear as fronteiras do conhecimento no momento em que foram escritos e realizados.

Consideramos que esses guias remetem às tradições na Geografia. Dentre as heranças da Geografia do século XIX, diferenças na natureza e propósito do conhecimento geográfico integram, obviamente, o corpo da disciplina, e emergem com particular vivacidade na difícil relação entre observação no campo e reflexão dos estudos (DRIVER, 2001). Há associação entre esse tipo de conhecimento e a formação de tradições geográficas (LIVINGSTONE, 1992) que, quando vitais, encerram 
continuidades e conflitos (MacIntyre apud LIVINGSTONE, 1992). Nesse sentido, dentre as estruturas nas quais as tradições são praticadas, a universidade constitui ambiente propício para observar quais tradições os diferentes geógrafos têm recorrido para praticar sua Geografia. $\mathrm{O}$ trabalho de campo como releitura da tradição das explorações e grandes viagens do século XIX, bem como a apresentação de dados primários, contribuem ainda hoje para o reconhecimento tácito de importância para a Geografia.

No Brasil, parte dessa tradição na Geografia pode ser resumida nos seguintes termos : "desde a origem da geografia moderna, todos os grandes mestres não seguiram outros métodos [observações diretas no campo], o único em verdade que pode libertar a produção geográfica do trabalho livresco e do vão palavrório sem base científica e sem nenhuma relação com a vida do Globo" (RUELLAN, 1944:45). Essa concepção não é exclusiva do autor. Ela reflete em realidade a própria tradição do modo de se fazer Geografia naquele período :

\begin{abstract}
Diretamente influenciada pela Geografia Francesa, já tradicionalmente refratária à teorização, a Geografia Brasileira fez do trabalho de campo, do contato direto com a observação, uma atividade não apenas fundamental de pesquisa, como também de aprendizado. Não seria exagero afirmar que foi no trabalho «no campo» - e não nas faculdades - que a primeira geração de geógrafos obteve, verdadeiramente, a sua formação (ABREU, 1994:25).
\end{abstract}

Tradição não implica, porém, em naturalização. Não obstante o fato de Livingstone e Driver tratarem dos conhecimentos acumulados pelos exploradores, a questão da credibilidade das informações levantadas no campo é ainda pertinente. Será ainda mais pertinenente cada vez que os relatos sobre o campo forem omitdos na construção do objeto. Em outro paralelo, não se trata, assim, como no passado, de afogarmo-nos em informações de manuais sobre o que e como observar (DRIVER, 2001), tal como no artigo de Ruellan, ou como na concepção de Aroldo de Azevedo assinalada por Abreu (1994), mas enfatizar o contexto de sua produção.

Há, no entanto, o sentimento de urgência em explicitar a gênese, os questionamentos e as modalidades de trabalho de campo na evolução da Geografia e, mais especificamente, seu desenvolvimento num mundo cada vez mais virtual e, contraditoriamente, preguiçoso no sentido de ouvir o outro e refletir sobre o próprio objeto de pesquisa. Para aceitar plenamente as considerações de Stoddart e Adams sobre a necessidade de se conhecer o que pensam os geógrafos e como fazem seus respectivos trabalhos de 
campo, é necessário, antes de mais nada, tomar conhecimento de como esses trabalhos são construídos/desconstruídos/reconstruídos. O próprio conceito de trabalho de campo tem mudado ao longo do tempo e nas diferentes regiões, motivo que suscita publicações que tratam dessas questões, como o livro de Gerber e Chuan (2000). Esse tipo de reflexão ainda está bastante incipiente na Geografia brasileira.

É preciso explicar as lacunas e os silêncios sobre o efetivo papel do trabalho de campo na (re)construção da pesquisa. Nesse sentido, chama a atenção o fato de a quase totalidade dos trabalhos mencionados não levar em conta, nas respectivas referências bibliográficas, a produção bastante expressiva dos Guias de Excursão publicados junto com os Anais dos Congressos de Geografia. Evidentemente, não se trata de adotar como dogma metodológico os guias de excursão, ao contrário, como sinaliza Cefaï (2003 :210) "se quisermos entender uma ciência, em primeiro lugar não devemos nos voltar para as teorias ou descobertas, mas obervar o que fazem os cientistas". No mesmo registro, Stoddart e Adams (2004) assumem que não é possível entender o que os geógrafos pensam e argumentam se não entendermos suas ideias sobre o trabalho de campo e sobre as várias maneiras de empreendê-lo. É nesse sentido que essas excurções apresentam a possibilidade de começar a apreender o sentido da dimensão espacial ou a leitura do espaço.

A recuperação do material de excursões e de sua crítica é antes de tudo objetivo de natureza epistemológica. Não se trata de recuperar, ou pior, lamentar a tradição perdida, mas de trabalhar a dimensão crítica sobre uma modalidade de trabalho de campo. O reconhecimento, seja das formas, seja das características da paisagem, indica a permanente transformação de determinado espaço. Para analisar cada um dos roteiros, é preciso lembrar que foram as opções dos geógrafos que definiram o trajeto, os acidentes geográficos e pontos a serem observados ou a evidência de rupturas e descontinuidades em oposição aos processos de articulação regional favorecido por sistemas distintos de comunicação.

$\mathrm{O}$ segundo ponto refere-se às relações entre a realização do trabalho de campo e a pesquisa. Em grande medida, o esvaziamento do pensar o trabalho de campo advém da produção em série: uma dissertação ou tese não encontra nexo no próprio fazer senão como elo de uma cadeia de produção. Essa perspectiva imprime ritmo de campo de e para a pesquisa de outrem. Na construção do objeto, toda consideração torna-se elemento perturbador da ordem de encadeamento: alguém já pensou o campo, alguém o organizou, portanto, meu campo é importante. Esta consiste, no meu entender, em exemplo bastante elucidativo daquela tradição inicial da 
formação dos geógrafos à qual Abreu (1994) se referia: de modo inconsciente, parte-se do pressuposto que o campo é a Geografia.

$\mathrm{O}$ terceiro ponto concerne à possibilidade de grupos e de objetos de pesquisa constituírem a base da investigação em Geografia e como, apesar das restrições em termos de financiamento, o trabalho de campo permanece como método que fundamenta o conhecimento empírico nas ciências sociais. O campo como método legítimo da Geografia parece, a partir da análise precedente, prescindir de qualquer discussão mais aprofundada dessa singularidade geográfica, ignorando por completo essa tradição em outras ciências sociais. As referências bibliográficas apresentadas nos diferentes artigos consultados ilustram esse ponto. Para finalizar, lembramos que entre o empirismo inconteste e a descrição dialógica da relação sujeito-objeto (CLIFFORD, 1998), há um leque amplo de estratégias de pesquisa que precisam ser explicitadas.

\section{Conclusão}

A discussão realizada neste artigo aponta para problemas que encontram explicação em posicionamentos que vão mais além do terreno da pesquisa individual. Contradições, impasses metodológicos, paradoxos, saltos escalares são aspectos frequentemente ignorados na concepção das pesquisas e do trabalho de campo. $\mathrm{O}$ amplo leque de estratégias de pesquisa requer a explicitação da estratégia de apreensão da realidade, que cria novos campos que propiciam outras possibilidades de apreensão da realidade.

Insistimos nas estratégias de pesquisa como intencionalidade da qual o trabalho de campo não pode escapar. Tentamos indicar a necessidade de superar aquilo que consideramos o entrincheiramento na (re)construção permanente do objeto de pesquisa, isto é, a importância do campo em si sem relação com o quadro teórico que constitui a chave de toda interpretação. Entrincheiramento ou insularidade acabam por fragilizar parte das pesquisas quanto à capacidade de enfrentamento de questões metodológicas. Em várias oportunidades foi possível notar que a fragilização faz-se presente na ausência de explicitação do papel do campo nas dissertações e teses - mais atenção vem sendo dispensada aos equipamentos a serem levados ao campo do que às reflexões e indagações sobre como esse "instrumento clássico da Geografia" nos obriga a conduzir de um ou de outro modo nossas pesquisas, a produção de informação etc. 
Por fim, este trabalho teve a intenção de provocar indagações e a ambição de apresentar reflexões sobre o atual status do trabalho de campo em Geografia a partir de minha experiência na condução do semináriodisciplina no âmbito do Programa de Pós-Graduação em Geografia da UFRJ. Deve ser, portanto, tomado tal como ele é : reflexão pessoal ora compartilhada.

TRABALHO DE CAMPO NA (RE) CONSTRUÇÃO DA PESQUISA GEOGRÁFICA: REFLEXÕES SOBRE UM TRADICIONAL INSTRUMENTO DE INVESTIGAÇÃO

Resumo: Este artigo apresenta reflexões sobre o trabalho de campo na construção/ desconstrução/reconstrução de objetos de investigações geográficas, a partir da experiência de seminário-disciplina em nível de Doutorado. Argumenta-se que um dos principais problemas dos geógrafos em formação é o caráter pouco reflexivo na construção ou reconstrução do objeto de pesquisa e que reflete na ausência de considerações sobre o trabalho de campo, antes e durante a realização da pesquisa, na desconstrução/reconstrução de objetos de investigações geográficas que incluam a necessária discussão sobre as tensões internas à própria disciplina.

Palavras-chave: trabalho de campo, Geografia, pesquisa.

(RE)CONSTRUCTING GEOGRAPHIC RESEARCH THROUGH FIELD-WORK: REFLEXIONS ABOUT A TRADITIONAL INSTRUMENT

Abstract: This article discusses the field-work in Geography. I argue that geographers are not interested in discuss the field-work as part of their object construction. This assertion raises the question of whether students in different researches will really connect the field-work with their thesis. This paper addresses one key question concerning this point: what role does $\mathrm{PhD}$ play in shapping, influencing students choices of research's practices like field-work?

Keywords: Geographical field-work, Geographical research 


\section{BIBLIOGRAFIA}

ABREU, M. A. 1994. O estudo geográfico da cidade no Brasil: evolução e avaliação- contribuição à história do pensamento geográfico brasileiro. $R B G 56$ (1/4): 21-122, jan-dez.

ALENTEJANO, P. R. e ROCHA-LEÃO, O. 2004. O trabalho de campo: uma ferramenta essencial pás os geógrafos ou um instrumento banalizado? Boletim Paulista de Geografia. São Paulo (84): 51-67.

CÉFAÏ, A. 2003. L' enquête de terrain. Paris: La Découverte.

CHELOTTI, M. C. 2009. Apontamentos sobre o trabalho de campo na Geografia: a contribuição da Antropologia para proposições geográficas. Disponível em www.revistamirante.net. Ultimo Acesso: setembro de 2009 CLIFFORD, J. 1998. A experiência Etnográfica. Antropologia e Literatura no século XX. Rio de Janeiro: Editora da UFRJ.

DAUDEL, C. 2008. Jean Demangeon Géographe de terrain. Paris : L'Harmattan, 2008.

DE MARCOS, V. 2006. Trabalho de Campo em Geografia: reflexões sobre uma experiência de pesquisa participante. Boletim Paulista de Geografia n. 84.

DEL GROSSI, S. R. 1992. Trabalho de campo em Geociências: sugestão de um modelo de roteiro. Uberlândia, EDUFU. Revista Sociedade \& Natureza, ano 4 (7 e 8) jan./dez

DeLYSER, D. e STARRS, P. 2001. Doing fieldwork: editors introduction. The American Geographical Society 91 (1-2): iv-viii.

DRIVER, F. 2000. Editorial: Field-work in Geography. Transactions. Institute of British Geographers 25(3): 267-268.

2001. Geography militant: cultures of exploration and empire. Oxford: Blackwell Publishers, 2001.

FONSECA, F. P. e KUVASNEY, E. 2009. Trabalho de campo multidisciplinar: insústrias, assentamentos e unidade de conservação (Vassunga) ao longo da via Anhanguera. Disponível em http://www.geografia.fflch.usp.br/

publicacoes/geousp/geousp13/geousp13_notas_padovesi_kuvasney.htm.

Último Acesso: setembro 2009.

GERBER, R. e CHUAN, G. (ed.) 2000. Geography: Reflections, Perspectives and Actions. Dordrecht: Klumer Academic Publishers

KAYSER, B. 1985 (1977). O geógrafo e a pesquisa de campo Teoria e Método. São Paulo: Seleção de textos AGB (11): 25-40. 
LACOSTE, Y. 1985 (1977) A pesquisa e o trabalho de campo: um problema político para os pesquisadores, estudantes e cidadãos. Teoria e Método. São Paulo Seleção de textos AGB (11): 1-23.

LATOUR, B. 1994. Jamais fomos modernos. Rio de Janeiro: Editora 34.

LIVINGSTONE, D. 1992. The Geographical Tradition Oxford: Blackwell.

MASSEY, D. 1999. Space-time, "science" and the relationship between physical Geography and human Geography. Institute of British Geographers, 24: 261-276.

PIRES DO RIO, G. A. 2008. "Gestão de Águas: um desafio geoinstitucional". In OLIVEIRA, M P et AL (org): O Brasil, a América Latina e o Mundo: espacialidades contemporâneas. Vol 1. Rio de Janeiro: Lamparina: ANPEGE.

ROBBINS, P. 2007. Nature Talks back: studing the economic life of things In: TICKELL, A et al Politics and Practice in Economic Geography. Londres: Sage Publications.

RUELLAN, F. 1944. O trabalho de campo nas pesquisas originais de Geografia regional. $R B G$ VI (1): 35-45.

RUA, J. 1997. Para melhor se entender a Geografia Agrária. In GeoUERJ 1,1997 .

SUERTEGARAY, D. M. A. 2002. A pesquisa de campo em Geografia. GEOgraphia (7): 92-99.

SWYNGEDOUW, E. 2001. "A cidade como um híbrido: natureza, sociedade e 'urbanização-cyborg'" in ACSELRAD, H. (org.) A duração das cidades: sustentabilidade e risco nas políticas urbanas $83-104$, Rio de Janeiro: DP\&A.

TRICART, J. 2006 (1977) O campo na dialética da Geografia. Geografia ontem e hoje. Revista do Departamento de Geografia da USP (19):104110. Disponível em http://www.geografia.fflch.usp.br/publicacoes/rdg. Último acesso: setembro 2009.

SERPA, A. 2006. O trabalho de Campo em geografia: uma abordagem teórico-metodológica. Boletim Paulista de Geografia (84): 7-24.

STODDART, D. R. e ADAMS, W. M. 2004, Fieldwork and Unity in Geography. In: STODDART, David R e ADAMS, William M (ed) Unifying Geography: common heritage, shared future. Oxford: Routledge.

Revista GEOgraphia - UFF

Data de submissão do artigo: 10/02/2011 